\title{
ANOMALOUS COGNITION BY TWO PUTATIVE 'PSYCHICS'
}

\section{INTRODUCTION}

Abbreviations - Inv $=$ Investigator, CoInv $=$ co-investigator, B $=$ first 'psychic', SS = second 'psychic', $\mathrm{D}=$ Inv's daughter. Betel (Betle) leaves $=$ from the creeper Piper betle L used in Sri Lankan rituals.

This investigation of anomalous cognition was done by a scientist, trained in the methods of modern natural science, to explore phenomena apparently outside the paradigms of modern science and to bring the paranormal to serious attention by scientists. The methods are described in (tedious) detail in presenting a novel phenomenon.

\section{METHODS}

Sessions $1-5$.

B's 'shrine room' was small, ill-lit with only 4 oil lamps. There were several pictures with non-reflecting surfaces, of deities, on a-shelf on one side of the table at which he sat. There were 10 similar pictures, also with non-reflecting surfaces, on the wall behind him. The only two doorways in the room were covered with cloth curtains. The walls of the room were non-reflecting and there were no pictures on the wall behind the investigator seated at the table opposite B. The low ceiling was of red cloth.

On the small table were 4 betel leaves arranged as a cross, with a small bottle of supposedly 'charmed' water, placed in the centre of the 4 leaves. (Did the bottle function as a crystal ball in sessions of traditional clairvoyants?) Between the bottle and the client was a chart on which was a diagram of the 12 zodiacal signs in celestial order, with the symbols of the 5 planets, the sun and the moon, and the 2 nodes, distributed according to some criterion of B's. There were 6 small sea shells also on the diagram. The small bottle, B said, contained water that had been activated by chants or 'mantrams'. Inv was asked to write his questions on a slip of paper, crumple it to a ball and place the ball on the chart. At no time did B touch the crumpled ball, nor was he able to read what was being written on the slip as this was done below the level of the surface of the table while the slip was on the client's knee. He requested that the test slip be crumpled into a ball be thrown with the shells on the chart and then removed; the shells alone were then thrown several times. 
When asked why the slip on which the questions (or Zener card symbols in later experiments) were written, had to be crumpled, B replied that the ball could then be thrown with the shells on the zodiacal chart-an essential step in his procedure; he also said that this chart involved astrology. (Since the slip had to be crumpled, the option of using the Zener cards themselves in later experiments, described below, did not arise). Sometimes he would ask that a number below 10, or a figure below 108, the name of a deity, or the name of a flower be stated. He then recited some stanzas and proceeded to 'read' what was written on the crumpled slip of paper, while intermittently gazing into the bottle of water; this could not have served as a magnifying glass for reading, because the crumpled slip had, by then, been removed. B appeared to do 'numerology' and astrology with the figures and data given.

On the 5 preliminary occasions, a total of 14 questions were presented to him, all written in his language, Sinhala, and in one, two or at the most, three words. There were 2 or 3 questions on each slip. The writing was done on slips of paper placed on the experimenter's knee, below the level of the surface of the table; each slip was crumpled before it was taken up to be placed on the chart on the table. There was apparently no way in which B could have directly read what was written (or being written) on the slip because the slip was well below his line of vision, its writing surface was shielded by a cupped hand, the lighting was very low, and there were no reflecting surfaces. No 'sensors' of objects or other electronic devices were felt on the under surface of the table.

Each question was denoted by one, two or at the most three words, allowing him leeway to expand on the question. On all occasions, he identified exactly, each question and in proper sequence. Once he did change the order, 1, 3 and 2 having said that he will take question 3 before 2 . He commented on the context of each question correctly, and made predictions; the correctness of his comments is discussed below. As later events turned out, however, his predictions were wrong. At this stage, and as far as B's identification of the questions went, the same question that Taylor (1980) asked in the Introduction to his book prompted itself-."Is it possible repeatedly to obtain results that are statistically significant when subjects are tested for knowledge of (or reactions to) external stimuli (unknown and uninferable to the subject) under conditions that safely exclude the recognized sensory process?" (Taylor 1980).

Session 6.

The tests were all done with a pack of Zener cards and with his system of slips of paper on which were drawn the target symbols. The card runs were done in the prescribed standard manner (Basic Technique of Rhine \& Pratt 1957) but B requested that the runs be done in batches of 5 symbols written on each slip in each run, and not with all 25 Zener cards at once or with the cards themselves, as in the standard Zener card run.

In this session, B was not told of the symbols on the Zener cards or how many of each symbol there were in the pack. It was merely said that there were 25 cards with a simple symbol on each card. The symbols, he was told, were, "for example, a triangle or a tree", neither of which is on the cards. The symbols in order from a shuffled-cut pack, were drawn vertically on slips, 5 on each slip. The vertical format of the series of symbols accorded with the vertical format of the cages in the record sheet for answers. After the first throw of shells with the crumpled ball, he asked that the ball be taken away and put it into the investigator's pocket. After a few more throws of the shells, he proceeded to write what he 'saw' or 'read'. 


\section{$1^{\text {st }}$ run}

B's first 'seen' symbol was correct while the next 4 were incorrect although he had drawn a square thus identifying, but misplacing, one of the symbols. The remaining 3 had vague resemblances to the 'sent' symbols, a circle, a cross and a square, but in incorrect sequence.

\section{$2^{\text {nd }}$ run}

Four of the 5 symbols were different from those in the $1^{\text {st }}$ run, and he scored $3 / 5$ hits. Not only was he able to identify the 3 symbols, he was also able to identify their sequence. Similar reproduction of simple target designs was reported in the Proceedings of the S.P.R., 1884, vol. II (see also Inglis 1992). B was then shown the Zener symbols and the results of his 'readings'.

\section{Session 7.}

The Zener card symbols were now known to $B$. A series of Zener symbols was written on 2 slips of paper, 5 on each, and presented to B as in session 6 . Since the series was written on the left side of the slip, orientation (top to bottom) could have been inferred by B, if at all he 'read' the slip.

\section{Results}

B's score of correct 'hits' was $10 / 10(100 \%)$; the sequence too was correct. There was no check list of the symbols from which the sequence could have been clairvoyantly 'read', while the crumpled ball was impervious to visual 'reading'.

As a further check on the integrity of his psychic apparatus, B was asked, in the usual manner, a personal question, also written in Simhala, on a slip of paper-a loss. B read it as follows- you ask about a loss. This item has been taken by an outsider who came into your house, and you will not get it back". Indeed that is what was concluded before B's reading. B, however, did not name the lost item.

Session 8.

\section{$1^{\text {st }}$ run}

Inv's daughter D, had drawn vertically, unseen by him, 5 symbols on each of 5 slips of paper, in their order in a shuffled-cut pack of Zener cards. On the back of each slip was written the number of the slip, eg., al, so that each could be picked up in turn and presented to $\mathrm{B}$ as a crumpled ball. These slips, before they were crumpled, were inserted into an envelope which was sealed by $D$. The list of 25 symbols in order was written by $D$ on a check-list, unseen by the experimenter, on a separate sheet of paper which was also inserted by her into an envelope, sealed and retained by her for later independent verification of B's hits.

The session began with the $1^{\text {st }}$ slip, identified by the number written on its back, taken by Inv from the envelope, without looking at the symbols drawn on it. The crumpled ball was taken away by Inv on B's request, after the first throw and the shells alone were thrown again.

Inv did not see the symbols drawn by D or know their sequence, at any stage of the test. There was no way in which B could have seen the symbols drawn before or after the slip was crumpled.

On the $1^{\text {st }}$ slip, B said, "all looks dark; there is nothing to be read. Open the slip and have a look". The roon was ill-lit with only 4 small oil lamps and the investigator himself could not read or even see what D had supposedly written on the slip. In the event that the other slips too had been inadvertently left blank, this run was abandoned. Does this failure 
indicate that the visual factor (clairvoyance) is more important than knowing what the writer had in her mind in writing the symbols (telepathy)?

\section{$2^{\text {nd }}$ run}

The above procedure was repeated except that the 5 symbols on each of 5 slips of paper were written by Inv, with a separate check-list of the symbols, selected in order from a re-shuffled-cut Zener pack. With each crumpled ball, the shells were thrown on the chart 5 times, once for each symbol. The crumpled ball was removed from the chart after the first throw, on B's instructions

\section{Results}

After both runs, and on checking the scores in a well-lit room, it was the case that D had indeed drawn 5 symbols on the $1^{\text {st }}$ slip but the pencil impressions were so faint (made even more illegible on crumpling) that they could not have been read in the darkness of B's ill-lit room.

B's 'seen' records in the $2^{\text {nd }}$ run were compared with the 'sent' target symbols, both on the opened-up crumpled balls (in their sequence from their numbers written on the reverse) and on the check-list, and were found to be entirely identical, in sequence as well, on the 5 slips. That is, his score on this $2^{\text {nd }}$ run was $25 / 25(100 \%)$.

Modifications of procedure included writing the symbols and crumpling the slips outside B's house. This was to use the 'constructive replication' method of Lykken (1968; quoted by Alcock, op.cit.): "By not imitating the original experimental set-up one reduces to some extent the likelihood that artefact was responsible for the results".

\section{Session 9.}

This session was with a Colnv, a senior professor, quite sceptical about any 'paranormal' claims.

Runs with Zener card symbols were done as before according to B's procedure. It was intended to do 2 runs; the $1^{\text {st }}$ with symbols drawn by Inv from a shuffled-cut pack of Zener cards, 5 symbols on each of 5 slips. The symbols were drawn 2 days before, at the CoInv's house, observed by his son (M). In the $2^{\text {nd }}$ and $3^{\text {rd }}$ slips, only 4 symbols instead of 5 were written. On the $4^{\text {th }}$ and $5^{\text {th }}$ slips one Zener symbol on each was replaced by the Greek letters $\alpha$, and $\beta$ respectively. The numbering of the $1^{\text {st }}$ slip was on the centre, with the stroke ' $l$ ' (just a short line from which the orientation of the slip and therefore the sequence of the symbols, could not have been determined). The $2^{\text {nd }}$ slip was similarly labelled and the figure ' 2 ' could have indicated the orientation. Slips 3 and 4 were labelled with 3 and 4 dots respectively on the centre of the reverse side. No orientation was possible on these two slips. The $5^{\text {th }}$ slip was unlabelled but was identified as the fifth by its having been crumpled after it was written upon. Slips 1-4 and the crumpled ball of slip No.5 were inserted in order individually, into envelopes which were sealed by the investigator in the presence of the co-investigator and $M$. The entire sequence of symbols in the $1^{\text {st }}$ run from the Zener pack, was entered by Inv on a separate check-list which was inserted into an envelope which was sealed and given to $M$ for safe-keeping and checking after the tests.

CoInv and Inv proceeded as before with each slip in order. Inv pretended to write the symbols anew, as on previous occasions, in B's room. Each slip was crumpled by him below the level of the table top, totally invisible to B who was seated at the opposite end of the table. The crumpled ball was then placed on the table and while B did not touch the ball, 6 sea shells and the ball were thrown as before, on the chart. After each slip (now as the crumpled ball) was read after the initial throw, the ball was put into Inv's pocket for later verification of 
hits. B proceeded to write on the 'seen' column of the record sheet which was given to him, the symbols in the order in which they were written on the slips. While reading the $2^{\text {nd }}$ and $3^{\text {rd }}$ slips, B said that only 4 symbols were visible on each. After the $3^{\text {rd }}$ slip was read, B said "that's enough for today", and the session ended prematurely.

\section{Results}

B's records of the Zener symbols matched correctly with the list of symbols on the three slips and with those on the check-list. He thus scored 'hits' of 13/13, with 2 correct blanks, only 3 slips having been read, slips 2 and 3 having had only 4 symbols each; accordingly he 'read' and recorded only 4 symbols for each of these 2 slips. He was also able to 'read' the symbols in their original sequence despite the slips having been crumpled and particularly with slip 3 which had its number depicted only by 3 dots on the reverse face of the slip, from which the orientation of the slip and hence the sequence of the symbols, could not have been 'guessed'.

Session 10.

Further experiments were made more rigorous. A senior Laboratory Technician (LT), wrote out, 9 days prior to this session, the series of symbols from a shuffled-cut pack of Zener cards, 5 on each of 5 slips of opaque paper; items were unknown to Inv and CoInv. A separate check list of the series was made and sealed inside an envelope, and retained by him. The slips and check list were written unseen by Inv and CoInv-10, an academic who was sceptical of psi.

Slip No.1 was lightly labelled ' 1 ' on the top left corner of the reverse of the slip, inserted into an envelope which was sealed by the writer. Slips 2, 3, 4 and 5 were unnumbered and were crumpled into tiny balls by the writer and each was inserted into an envelope which was labelled accordingly, for the use of the investigator. Colnv- 10 presented the run.

$B$ requested that only CoInv- 10 be present in the room. After several attempts at throwing the shells with the crumpled ball of slip No.2, B said he could not establish rapport with CoInv-10 and the session ended. B said that Colnv-10 appeared to doubt his psi-capability, and was therefore was an unsuitable investigator.

Although both Colnv-9 and CoInv-10 were sceptical of psi, Colnv-9's runs were successful while Colnv-10's, weren't. The difference was probably that Colnv-10 appeared 'young', for B had warned Inv before he joined him in this session, that he did not like young (and hence, according to $\mathrm{B}$, impatient, arrogant, immature, impulsive) sceptics, investigating him. It was evident that, even from the beginning of this session, B appeared to be antagonistic towards CoInv-10.

B continued the run with the Inv alone; $B$ said he would try a new method of 'reading' and recording the symbols. Slip No.5 (which had been crumpled 9 days before) was taken from the sealed envelope, placed it on the chart, and thrown with the 6 shells a few times. B requested Inv to select any 3 betel leaves (which Lankan clients offer with the consultation fee) from a large pile on his table, place them before the bottle of 'activated' water, and then place them on Inv's chest. He then came beside Inv and touched the top leaf, recited some stanzas, and said that the list of symbols would appear on one of the 3 leaves chosen by Inv. Of course, not knowing that a leaf would be 'written upon', it did not occur to Inv to check each leaf after he took them up. B touched only the top leaf (of the 3 ), and only after they were placed by Inv on his chest. 


\section{$1^{\text {st }}$ run}

Finally, B took one of these 3 leaves, placed it against the light of an oil lamp, and showed Inv the list of symbols which appeared etched on the leaf. He said he 'did' this-paranormally - to convince CoInv-10 that his performance was neither magic nor fraud and wanted me to call back CoInv-10 into the room to show him the leaf. At no time did B take away a single leaf or write anything on it to be seen by me, the investigator. B wrote out his readings of the symbols, again, for a permanent record on a record sheet.

All 5 symbols were later checked with those on the check-list (opened in the presence of LT and Colnv-10), and with those on the unfolded, crumpled balls, and were found to be correct in symbol and sequence. LT had substituted two Zener symbols with R and $\mathrm{K}$ respectively. Neither CoInv-10 nor Inv was aware of their position on the slip. B was not told that some symbols would be replaced by new ones. It is remarkable that the symbols and their sequence were identified by B despite the opaque paper on which they had been written, had been crumpled. If either B or a 'spirit' (see Discussion below) was 'reading' them in the conventional visual sense, it must have taken some effort to decipher the twisted forms of the symbols on the crumpled slip.

\section{$2^{\text {nd }}$ run}

Inv took slip No.I from the sealed envelope, crumpled it and repeated the throws. B reverted to his usual procedure, without the betel leaves, and proceeded to write the symbols on a record sheet.

On comparing B's records of the 2 nd run with the records on the check-list and on the opened-up crumpled ball of slip No.l, his 'hits' were $5 / 5$ and in the correct sequence.

Session 11 .

Colnv-11 senior academic had had several valid experiences of precognition during waking hours; no previous experiences with psychics.

Symbols were drawn by random selection on a computer program (Corel art), with the selection of codes (but not the symbols) done by CoInv-10's wife. Colnv-10 was unaware of the symbols. Two slips were used. They were each inserted into an envelope, brought to our department and crumpled by CoInv-10, and re-inserted into each slip's envelope and sealed. Five symbols on a $3^{\text {rd }}$ slip were drawn, unseen by Inv or CoInv-10, by D, chosen by her from the 5 Zener symbols and 7 letters of the Greek alphabet. Inv suggested that one of the 5 symbols be drawn in pink and another in purple. Inv was unaware of which ones were coloured. There were no check-lists for the 3 slips.

CoInv-11 presented the 3 crumpled balls in the usual manner, a computer-generated slip, D's slip and the second computer-generated slip. B 'read' and drew each set as before. While 'reading' the $2^{\text {nd }}$ slip B said he sees 2 colours. The $3^{\text {rd }}$ set, he said, was quite complicated but proceeded to draw the symbols.

\section{Results}

$1^{\text {st }}$ run

The $1^{\text {st }}$ set of computer-generated symbols had 4 symbols. The computer print-out when closely examined had double lines on all 4 symbols which however, at a rapid glance, 
appeared to be drawn in a single thick line. B reproduced all 4 correctly and in the original sequence.

\section{$2^{\text {nd }}$ run}

$\mathrm{S}$ had drawn 5 symbols in vertical order, beginning with the Greek $\gamma$ with a bloated stem, followed by the (Zener) wave, then the Greek letter $\beta$, a thick walled (Zener) circle in purple, and last, the Greek $\lambda$ in pink. The orientation of D's list was identifiable by the Greek letters at the top and at the bottom. B reproduced exactly the symbols but had written them upside-down, in reverse order. It is noteworthy that although $\mathrm{D}$ had drawn a $\beta$, the crumpling of the slip had smudged the purple ink of the circle onto the $\beta$ which then appeared unrecognizable as $\beta$; this means that B 'read' or interpreted what was on the crumpled slip at the time of 'reading' and not what was originally written on it.

\section{$3^{\text {rd }}$ run}

$\mathrm{B}$ reproduced exactly, the 4 computer generated symbols, with the double line on each symbol, and in correct sequence.

It is to be noted that the 3 slips of this session had no check-lists which we had in previous runs. One wonders whether the absence of a correct orientation of the $2^{\text {nd }}$ slip, (unlike in previous sessions when a check-list was available-though $4 \mathrm{~km}$ away) could be attributed to the absence of a check-list, which, if it were available, B might have 'read at a distance'. The reading of the 3 rd slip in the $2^{\text {nd }}$ run was the first instance of the recognition of colours by $\mathrm{B}$.

\section{Session 12 .}

Two questions were written on a slip of paper which was crumpled and inserted into an envelope, $2 \mathrm{~km}$ away from B's room. After the first throw with shells, B asked that the ball be removed and put into Inv's pocket. He then proceeded to say that there were 2 questions, and he wrote them out, exactly letter for letter.

The first was in Sinhala "my good friend" and the second in Latin "iter meum transoceanum". Inv having numerous good friends but with just one of them in his mind on this occasion, B's ability to focus on this particular person (telepathy) was tested, despite the non-specific question. He identified the written question correctly (+ clairvoyance) but failed to comment correctly on the person Inv had in mind (- telepathy). Although the question in Latin was correctly written out by B; his knowledge of Latin was not tested.

To investigate the possibility in all these sessions of $B$ having tampered with the crumpled ball on the table and having read it, unseen by the investigator, during the quarter-minute during which the ball lay on the chart. It took a separate test in which about a full minute was spent unfolding the crumpled ball, carefully, without tearing it. If B indeed did this, he would, in addition to unfolding it, have had to read it, record what was written and re-crumple it before replacing it on the chart, during that quarter-minute. Unless the co-investigators and Inv were under hypnosis during the sessions, it is unlikely that B defrauded in that manner.

\section{Session 13}

Colnv -13 , Surgeon, interested in the paranormal but had an open mind on its reality. $1^{\text {st }}$ run. 
Betel leaves (7, plucked from Inv's garden, $1 \mathrm{hr}$ prior to the test) were presented. The test object was a piece of paper on which was computer print-out of Corel Art diagrams chosen 'blind' by a colleague; he had selected, at random, numbers on the computer's key-board, which corresponded with diagrams which were unknown to him. This paper with the print-out was crumpled and inserted into an envelope by Inv before CoInv-13 took it for the session. Neither the computer operator, CoInv-13 nor Inv, was aware of the diagrams or the number of diagrams. The paper had been crumpled and inserted into an envelope which was then sealed, 3 weeks before the session.

$B$ requested from Inv that any one of the 7 leaves which Inv had brought be taken, placed on Inv's chest, and then placed on the chart near the bottle of 'charmed water'. B recited some stanzas and took the leaf and held it near an oil lamp's flame and said that the contents of the crumpled slip, now a ball, would be 'written' on the leaf. Indeed, they were, but only 4 out of 5 designs on the computer-drawn slip were recorded by B. B re-drew the designs on paper for a permanent record. The 4 were almost identical with the originals; the differences were that only the outline of the conical pile of bricks was present in B's records.

It was requested that B repeats his 'betel leaf etching' of session 10; Inv examined the leaves closely before one was selected for etching. Since they had been plucked, afresh from the creeper, they were all in pristine condition. At no time was B seen to be writing on the leaf. This was particularly looked-for especially because the etchings on the leaf appeared to have been made with a ball-pen; B too was also using a ball-pen for his 'calculations'.

$2^{\text {nd }}$ run

Colnv-12 had brought a slip with writings on it, and crumpled it just before the session. It was thrown in the usual manner. Three statements were requested by $\mathrm{B}$ from Colnv-13 -:"name 3 figures below 10, name a deity, and your ruling zodiacal sign?" The ball was thrown once with the shells and B then requested that the ball be removed. Seated next to CoInv-13, Inv removed the ball and placed it in his pocket. B had not touched the ball. B picked up a piece of blank paper from his table and said that the written contents of the ball would appear on the slip which he placed on our side of the bottle of charmed water. Indeed they did appear as seen through the thin paper; and the 'writings' were again almost identical with the originals-(1) a quotation in two sentences in English, "Vanity of vanities, All is vanity" (2) a quotation in Latin in 2 sentences, "Timeo danaos, et dona ferentes" (3) a complex diagram of 3 nerve roots in the human Brachial Plexus, (4) a quotation in German in 2 sentences, "Wer reitet so spat, durch nacht und wind".

Did B demonstrate 'psychokinesis' in addition to clairvoyance in this session?

Session 14.

CoInv-14, a Professor of Medicine, interested in the paranormal, had not witnessed a performance; open-minded about its reality. Colnv-14 had inserted 3 bank notes, each into an envelope which was sealed. B agreed that the note in its envelope could also have been crumpled but its large size might prove cumbersome for occupying a sector on the astrological chart.

$B$ requested that the envelopes be opened, the numbers written on a piece of paper which should then be crumpled and thrown on the astrological chart as before. Colnv-14 wrote out the serial numbers of 2 currency notes on a slip of paper which was placed on his lap, well below the visibility level of $B$. The dim lighting also would have made it unlikely that $B$ could have seen the writings. This was thrown thrice with the shells, following which $B$ instructed that 3 betel leaves (which Inv had plucked from his garden's creeper and given 
with the fee) be selected, drawn over CoInv-14's face, and then placed on Inv's chest (as before in session 10) and finally placed on the chart. B selected the top leaf and held it against the flame of one of the 5 oil lamps on B's table and said that the numbers would appear on the leaf; and they did The numbers were also written by B on a separate slip of paper for our records. The crumpled ball was unfurled and the numbers checked; the numbers on the leaf and on B's slip were identical with the numbers written on CoInv's slip of paper.

The writings on the leaf and on B's answer slip differed from CoInv-14's writing of the serial numbers, excluding the possibility of a direct copying of the originals on Colnv-14's slip, on to the leaf and B's slip (in the manner of a photocopy). The 'writing' on the leaf was similar but not identical with that on the slip, there were no similarities between CoInv-14's writing and those on the leaf and slip

Did session 14 again demonstrate clairvoyance and psychokinesis?

Session 15.

The foregoing results were communicated to a professional, academic parapsychologist, Professor Robert Morris, (Koestler Chair of Parapsychology, University of Edinburgh, UK, now deceased). He advised that further tests be done to exclude magic. Discussions were held with a local amateur magician who had earlier done a similar 'reading' of written items but with the use of sleight-of-hand, substitution of the crumpled ball, and direct reading of the original. It was agreed that a final test of the authenticity of B's performance as clairvoyance would require that the crumpled ball be so made as to prevent opening of the ball by $\mathrm{B}$.

Two 'balls' were made. One with 5 symbols written on a slip of paper which was then gummed before being crumpled and allowed to dry completely before presentation to $\mathrm{B}$. The symbols were duplicated on a check-slip retained by E. The second was similar except that at each stage of crumpling, marks were made across adjacent flaps. Opening of the ball would have made realignment of the marks difficult and their non-apposition in the event of opening could have been detected.

The magician suggested that Inv does the test with B using both balls. Taking in both balls, and explaining to B that this was a crucial and perhaps final test, he said he will read only one ball and Inv chose the gummed ball as being a more stringent test.

The ball was thrown with 6 shells as before and the ball was returned to Inv's pocket. B said this test was difficult but that there were 5 items written on the crumpled slip. This was correct. He then said that this test has been planned in doubt of B's competence (virtually correct) and that the 'mediumistic goddess' is displeased and if he is to read the contents, Inv should return, and suffer a penance before his reading. B appeared displeased. Several visits were made to explain the experimental, scientific procedure with attempts to falsify the reading, which we adopted in our efforts to decide whether B's performance is valid. B finally agreed to 'read' the original ball.

Session 16, 2 months after the original test with the gummed ball.

The magician suggested that Inv attends the session alone. The session commenced as before, with the original gummed ball of session 15, being thrown with the 6 shells on the chart. B wanted Inv to write out the figures from $1-108$ and delete any 5 figures from the list. B then began his 'calculations' (numerology?) after which he said, "I see a triangle". The original gummed slip of paper was opened in the presence of the magician and a former co-investigator with whom this test was planned. It took lnv some time, to carefully open the gummed and now dry ball, as the task was difficult, and the slip tore in several places (Fig. 1). 
It did not seem likely that B had opened the ball before Inv. It was identified as our original slip with a very small blue mark which had been placed inside, before the crumpling. B's writing was compared with those on this slip and on the check list. B's score was $5 / 5(100 \%)$. Although he began his reading by saying "I see a triangle" he had not drawn a triangle, until Inv asked him "what about the triangle?" A triangle had not been drawn on previous test slips. He had in addition drawn half a square which was not on the original slip. A difference between one of B's 'read' symbols and the originals, was that our 'plus' symbol + was written by $\mathrm{B}$ as a cross $\mathrm{x}$ (Fig. 1).

Comment- The gummed ball had not been opened before Inv opened it after B's test. This excludes fraud through sleight-of-hand by B with removal of the ball, opening it and reading its contents visually.

Session 17.

Three items were drawn by Inv on a slip of paper in vertical order, 2 mystical symbols from P.D. Ouspensky, selected by Colnv-13, and the third, a letter in Sinhala, copied from B's own handwriting. The slip was gummed on its edges and folded once; then crumpled after the gum had dried. As in previous sessions, the ball was thrown with 7 shells. Since Inv had taken 5 fresh betel leaves from his garden, B wanted him to take away the ball and re-throw 5 shells twice more. The ball was thrown again with the 5 shells and he said he "sees 3 items". He then told Inv to place the 5 leaves over the crumpled ball, and to then unfold the crumpled ball (which was done without re-opening it after the gumming) and tear it into 2 , and to tear the 2 parts again into 4 . The parts were then returned to Inv's pocket and he was then told to hold the 5 leaves against the oil lamp's flame near Inv while B chanted some stanzas. He wanted Inv to have a look at the leaf nearest the flame. This has etched upon it the 3 items which Inv had drawn on the slip. The torn fragments of the partially unfolded ball were re-aligned, in the presence of the co-investigator, to form the original slip, after opening the parts which were gummed. One etching was identical with that on the original slip. B's reproduction of the $2^{\text {nd }}$ complex Ouspensky symbol was only slightly in error, while the Sinhala letter too was identifiable as the original letter but its form was also not identical.

Comment-As in session 16, it did not appear that he had opened the gummed crumpled ball, although he transcribed its contents with almost total accuracy.

Session 18.

CoInv-15 (Consultant Virologist, discoverer of the SARS virus), who video-recorded the session. Test items- 3 symbols.

$\mathrm{B}$ wanted Colnv- 15 to remain outside the room until B was ready for the videoing. Inv had taken a crumpled slip containing symbols (unknown to him) drawn by D. B said that a new slip which he gave Inv, be written on. Inv wrote the 3 test symbols below the level of the table, out of B's vision, crumpled it and proceeded as usual to throw it on the chart with 6 shells. The ball after the first throw was returned to Inv's pocket. B wanted Inv to state 3 numbers below 10 , and proceeded to calculate. He then wanted Colnv-15 to enter the room and start video-recording.

Inv was asked to throw the crumpled ball again with the shells, to select some leaves from the 7 that he had brought from his garden, and to place them on his chest. He recited some stanzas and wanted Inv to inspect the leaves. On the second leaf were the 3 'sent' items etched correctly. 
He then asked Inv to hold the leaf before himself and again, having recited some stanzas, placed his hand on a blank sheet of paper on the table. The 3 items appeared drawn on the paper.

Comment-At no time during this session did B remove the ball away from the chart. The betel leaf etching was not further investigated. No evidence was seen on the video of $B$ having taken the ball away, opening it, reading it and replacing it on the table.

Final Session 19 with B.

Inv suggested that $\mathrm{B}$ attempts to read the original Zener cards and then symbols of cards written on the crumpled slip according to his usual practice. He declined saying that since the cards cannot be crumpled and thrown on the chart, this test is not feasible. However, he read correctly 5 symbols drawn, as usual with B, on a slip of paper which was crumpled before being thrown on the chart.

\section{Investigation of the second 'psychic' - SS.}

A second 'psychic' (SS) in Colombo, Sri Lanka, who, Inv was informed, makes the same sort of performance, was tested and twice after at an interval of a month, with a videoing of his performance on the $3^{\text {rd }}$ session. He was about 40 years of age, and said that he studied this technique, which he called a 'Malayalee' technique, in the west coast of south India. The Malayalees are reputed to be skilled in occult practices. He was told that we were experimenting on and researching his performance.

Session I-SS.

SS had a 7-sectored chart (different from that of B) on his table, without betel leaves or a bottle of 'water' as B had. He gave Inv a small square of paper and wanted 3 items written on it, on a wall-table adjacent to his table, with Inv's back turned towards him. The 3 items - No. 1 with 3 words, No. 2 with 2 words and No. 3 with one word, all unseen by SS during writing, and crumpling of the slip into a small ball before Inv returned to the table. He wanted Inv to state a number below 10, his birth date and his astrological chart's ruling sign. While holding the ball between his thumb and forefinger of his left hand, he then proceeded to calculate, and then stated the question-topics accurately but unlike B proceeded to comment accurately on each topic, on relevant matters which Inv had not written or told him of. In addition he made predictions which were written out and placed inside envelopes which were dated and sealed.

Comment- - SS did not remove the ball or attempt to open and read the contents. SS differed from B in that he was able to comment accurately on the context of each question, even when the written question was one-worded. In addition he made comments about Inv which were not written on the slip- "you now have a pain in your leg" which was correct; Inv had a troublesome ache in his hip and upper leg on which he had consulted a surgeon. On the $2^{\text {nd }}$ one-worded question, he made accurate comments which had been earlier and accurately referred to in the subject's astrological readings by another person, and which were correct in terms of actual occurrences.

Session 2-SS.

As before, 3 questions, each with 2 words were written on a slip of paper which was crumpled and placed on the chart. SS again, very accurately stated the written questions and commented on them accurately.

Session 3-SS. 
This session was video-recorded by a medical academic, from the start. A single worded topic was written on the slip, on SS's table with Inv's hand covering the slip. The lettering was small and could not have been read by SS at a distance of $1 \mathrm{~m}$. The same questions were asked from Inv - astrological ruling sign, birth date, a number below $\mathrm{I} 0$, and he wanted him to point to a vein on the reverse of a betel leaf taken randomly from the sheaf which contained the consultation fee. After the usual calculations he identified the topic of the written item correctly and commented, also correctly, on the affairs of the person referred to on the question. These, again tallied with previous astrological readings given by others.

Comment - the video recording clearly showed that (1) SS was looking away from lnv while he was writing on the slip covered by his hand, (2) while he held the ball between his thumb and forefinger, he did not take it away or open the ball and read the contents.

Session 4 - SS.

This session was to investigate whether SS's ability to read concealed writings was by telepathy or clairvoyance or through his special technique with calculations and perhaps numerology / astrology. SS was reminded of the Zener symbols. Two runs were done, the $1^{\text {st }}$ in the standard manner with Inv's knowledge of each card, which were placed face down on the table before him. The $2^{\text {nd }}$ run according to his crumpled-ball technique with the Zener symbols written on a slip of paper which was crumpled before his 'reading'.

$1^{\text {st }}$ run.

Five Zener cards were selected from the top of a shuffled pack placed face down on the table and each of the five was seen by Inv and placed on his chest while SS made his 'reading'. SS had no vision of the cards. Reflecting surfaces were checked for. SS wrote on a slip his 'readings' of the cards which were gone through at $1 / 2$ min intervals for each.

$2^{\text {nd }}$ run.

The symbols in the same order, were then written on a small slip of paper with a mark on the top of the slip to indicate the starting point, away from his desk and without visual access to SS, crumpled before Inv returned to his table and placed on SS's chart according to his usual procedure. With each symbol he made calculations and wrote down each symbol.

\section{Results}

$1^{\text {st }}$ run.

His readings, by the usual Zener card-reading test technique, were wrong - 0/5. $2^{\text {nd }}$ run.

Each symbol, written on a slip of paper, was 'read' by SS and written down with simultaneous calculations. All his readings were correct in symbol and sequence (5/5), although he had reversed the order in which Inv had written them.

Comment-This test showed that SS's reading ability was not through either telepathy (with Inv's knowledge of the symbols) or through clairvoyance on the Zener cards themselves, but through his special technique which involved the crumpled ball, his chart and calculations (numerology? astrology?). That astrological calculations were involved was shown by the conventional astrological chart which he used during his calculations.

In this respect his technique and correct symbol-reading ability was similar to those used by $\mathrm{B}$. 
1. "From the Rhine tests we know that quite small objects, down to $1 / 16$ " can be

observed (even down to $1 / 100$ " in some cases)" (Taylor, op.cit.). Our symbols presented to $B$, were about $1 \mathrm{~cm}$ square. Letters on SS's slips were $3 \mathrm{~mm}$-square.

2. An observer (not involved in these sessions) told Inv that he tested B with a question (also written on a slip of paper) relating to "my daughter". B 'read' the question correctly but failed to identify the falsity of it because this observer had no daughter. All Inv's questions to $\mathrm{B}$, were on valid or 'real' items; the capacity for correct identification of what is written (clairvoyance) has to be differentiated from the capacity for identification of the validity, reality or truth of what is written (telepathy).

3 . The use of slips of paper on which the symbols were written, eliminated cues from indicators on oft-used Zener cards or those handled by subjects; it could also have eliminated the problem of orientation-cues from the backs of Zener cards (Alcock op.cit.): "Nowadays, 'respectable' parapsychologists do not allow subjects to handle the cards, but that was not the case in the earlier days when the most successful demonstrations took place" (Alcock, op.cit.).

4. Writing the symbols or questions, and crumpling the slips of paper outside B's room, eliminated error or fraud through reflections off mirrors or shiny surfaces of pictures or walls (none of which was in B's room), from the investigator's spectacles, or even his corneas (Watson, 1974), or by inference from the movements of the pen in writing the symbols or questions.

5. With Colnv-9, a sceptic of psi before the sessions with B, as co-investigator and with the replication of B's successful hits both on Zener card symbols and on Colnv-9's personal question, the oft-documented 'sheep-goat' effect, observed with Zener card runs, did not seem to occur- “.... only believers will detect or experience psi...." (Alcock, op.cit.). Nor was there a 'decline effect', reportedly seen in Zener card runs, observed in the series of runs with B. "Gradually, in the course of a series of runs, their scores would fall to chance level" (Inglis 1985).

6. The observer himself (whether known to B or not, whether believer, open-minded or sceptical) did not seem to matter: Although both Colnv-9 and Colnv-10 were sceptical of psi, CoE-9's runs were successful while CoE-10's were not (session 10). Why B was antagonistic towards CoE-10 but cordial with CoE-9 in session 9, CoE-11 in session 11 and CoE-13 in session 13, is difficult to understand. "In parapsychology, as you may know by now, one of the major obstacles to experimentation is the interaction between the experimenter and what he would like to regard as his isolated experimental system" (McConnell, op.cit.). "........in the laboratory, too, emotional rapport between experimenter and subject is of decisive importance" (Koestler 1972).

The fact that Colnv-9 was previously unknown to $\mathrm{B}$, does not appear to have lessened B's score of successful hits.

7. Nor, apparently, was it the case, even with our rigorous planning of the tests to exclude error or fraud, that scores proportionately diminished: "A scrupulous experimenter, too openly preoccupied with precautions can produce in his experimental room a condition of stress and suspicion likely to be unfavourable to psi-functioning" (Thouless 1972). "When the experimenter thinks too much about his experiment, he may be changing crucial conditions" (McConnell 1983).

The use of slip No.5 in session 10, on which were written 5 Zener symbols, crumpled and then inserted into an envelope which was sealed at once, 9 days before the session, would 
have excluded any possibility of fraud through direct vision of what was written or being written in his room. The check-list, when available in some of B's sessions, was deposited 4 $\mathrm{km}$ away from B's room.

8. B and SS said that, having had an inkling of such a capacity, they developed it through studies in India and through meditation and mantrams (esoteric stanzas) and that the spirit of B's dead father with whom he communicates, has supported him in this work: "One other possible variable on the parapsychological plane has to be taken into account: the existence of discarnate intelligences, of the kind that are assumed to be spirits, intervening in trials. Intervention of this kind has commonly been reported in investigation of poltergeists, and occasionally in connection with ESP tests-for example, through unaccountable disruption of recording equipment at critical junctures. It is now more commonly attributed to 'exteriorization'- psychic energy emanating from a living person, or persons" (Inglis 1985). "If the subject guesses significantly above chance, he could be using any one of number of E.S.P. faculties. The most obvious is clairvoyance. Somehow, he is able to 'see' the card even though it is placed face downwards on the pack. On the other hand, it is just possible that the experimenter himself is clairvoyant and 'sees' the card in his mind. The subject then reads the experimenter's mind by telepathy. Another explanation might be that the subject has 'seen' into the future and has a more or less clear vision of the order of cards as they are revealed at the end of the experiment. He would then be gifted with precognition. Nor can we rule out the possibility that he has consciously worked out a particular sequence for the cards and has willed then to fall into this sequence during the cutting and shuffling. This would be psychokinesis" (Ellis 1974).

On some occasions when B scored successes, the experimenter was unaware of the symbols or their sequence as in session 13; this would exclude telepathy, unless the experimenter was himself clairvoyant. B's inability to expand correctly on a question, when it was not sufficiently specific, also probably excludes telepathy. Some questions might have given B sufficient cues to make logical and valid comments on them. SS, unlike B, was however capable of commenting at length on the context of even one-worded questions. That the symbols were written days prior to some sessions with B (eg. in session 13) would appear to exclude precognition followed by psychokinesis. Psychokinesis may have been involved in the appearance of the symbols, etched out on the betel leaf in the 'reading' of slip No.5 in sessions 10 and in $13 \mathrm{a}$ and on paper in $13 \mathrm{~b}$.

Could B have unfolded the crumpled ball, read it, and re-crumpled it, while we were under hypnosis? Colnv-9 and CoInv- 11 were with Inv during their respective sessions, and none of them experienced such a state. Moreover, the crumpled ball lay on the table for just quarter of a minute before it was taken away and put into Inv's pocket. The sealing of the slip with gum before crumpling (see note 9) and presentation to $B$, and the intactness of the gummed ball after 'reading', excluded any attempt by $B$ to open the ball and read the contents of the original slip.

The role of obscure occult factors, which B apparently resorted to, has also to be reckoned with. There are perhaps alternative or additional explanations of B's performance. Inglis (1989) considered 'sensory automatism' and 'motor automatism', so identified by Myers. Could B have 'heard' a 'demon's' or spirit's voice telling him (sensory automatism) what was written on the crumpled slips? Or were B's records of what was written on the slips, actually made "as if guided by another hand" (motor automatism or "psychography"), as suggested of Rudyard Kipling's writings? Indeed, when asked this pointedly, B replied that 
he does feel that it was not under his volition that he wrote his answers of the 'seen' symbols (see personal note on B).

The possibility of developing psi-capability is apparently shown in B's and SS's cases, as well as in the Indonesians (who use it for a worth-while cause), described below.

A parallel of B's performance (reading without direct visual access to written material) is that of some Indonesians (Merpati Putih Abadi Foundation, Division of Visually. Handicapped Rehabilitation, Jakarta, Indonesia), whose demonstrations of the training of the totally blind to see their way around (Obstacle Avoidance Phase) and to read print, "not Braille fonts" (Object Detection Phase, and Colour Detection) and the exercise to "sharpen and enhance the sensory powers") as a part of the community rehabilitation of the blind, was related by co-experimenter Colnv-1I from his first hand experience of these people at their demonstration at the Institute of Child Health near the Great Ormond Street Institute for Child Health, London, UK.

Apparently normal, young Indonesians, who had been trained in martial arts, self-defence including "seeing in the dark" and, perhaps meditation, and the acquired skills which were demonstrated, were able to read, while totally blindfolded by members of the hospital's staff as audience, print on the pages of books with their palms moving over. and not on, the pages as if scanning them, locate items specified by the audience (eg., a particular edition of a particular book from amongst many books in a cupboard), move around the room between numerous chairs and tables and people, amongst other feats which would normally require a clear vision of the layout of the room and its contents. It is noteworthy that the capacity to do all these feats, was developed in these individuals by training. Indeed the organisers of this demonstration, offer training courses for this capacity, to totally blind persons in Indonesia.

Another parallel is that described as 'Eyeless sight' of Rosa Kuleshova who was apparently able to 'read' and identify colours through her finger-tips (Ostrander \& Schroeder 1970). This capacity, too, was claimed to be amenable to 'learning', as when children were taught to repeat Rosa's feats.

A further parallel of these performances is the phenomenon of "Remote Viewing"; the examples documented in the book Mind over Matter (Kit Pedler 1981) are striking but the performances ("seen" data) of the two sensitives dealt with in this paper tallied fully ( $100 \%)$ with the 'sent' data, that are even more striking. May (1996) described remote viewing work of the US Department of Defense' STAR GATE Program; as with Pedler's cases, the correspondence of the target with seen images was not as complete as with the $100 \%$ hits obtained with B and SS.

What seems to be of primary importance is: "From the point of view of establishing the existence of the paranormal, however, the decision of whether telepathy or clairvoyance is responsible for the results is of less importance than the demonstrations which the results gave of ESP, not just at Duke but in trials in other universities" (Inglis I985).

9. Sceptics would, of course, have recourse to the idea of a conspiracy between E, all the co-examiners, and their aides. B was keen to demonstrate his capacity and to co-operate in these tests; while Inv and Colnv were impressed, they were just as keen to explore all avenues to exclude error and/or fraud. Whatever their plea; "It was of no use the investigators standing on their dignity and protesting their good faith; 'in all scientific inquiries the good faith of individuals concerned should form no part of the data on which the conclusion is to rest" (Inglis, 1992, p 323, quoting Horatio Donkin). "Ordinarily the weight of experimental 
evidence for ESP would long since have sufficed to convince doubters. By the early 1950s, unless there was a 'gigantic conspiracy involving some thirty University departments all over the world. and several hundred highly respected scientists', Professor Hans Evsenck of London University commented (and as a Behaviorist psychologist, his scrutiny of the evidence had been critical). 'the only conclusion of the unbiased observer can come to must be that there does exist a small number of people who obtain knowledge existing either in other people" minds or in the outer world, by means as yet unknown to science' " (Inglis, op.cit.).

If B was 'reading' the writing on the slips by some fraudulent method, it then remains to be explained why he did not score $100 \%$ when Zener symbols, unknown to him, were presented for the first time. It was after all through the same procedure of crumpled slips thrown on the table. One possible method of fraud involves sleight-of-hand, removal of the test ball, opening it without the experimenter seeing the act, and replacement of the re-crumpled ball on the table. It took Inv nearly 4 minutes to, even partially, open the gummed ball for verification after B's session. The gumming resulted in his tearing the slip in several places (Fig. 1), on opening the ball after the session to check whether B had fraudulently opened and read the writing on the slip during the session. This indicated that $B$ had not opened the ball during the session.

Session 16 showed that B achieved a score of $100 \%$ without evidence of the gummed ball having been opened.

I0. Can B repeat his performance in another room, outside his 'shrine room'? No, he replied. This 'shrine room' has been conditioned by his incantations ('mantrams'), pictures of deities, incense, and other occult or esoteric factors which do not make it possible to repeat the readings in any other room or venue. "There seem to be specific conditions in which telepathy can take place, and tring to examine it in a laboratory under controlled conditions is a little like trying to study the behavior of a dead animal" (Watson, op.cit.). 11. In answer to Taylor's question, "Is it possible repeatedly to obtain results that are statistically significant when subjects are tested for knowledge of (or reaction to) external stimuli (unknown and uninferable to the subject) under conditions that safely exclude the recognized senson process?" (Taylor, op.cit.), apparently B and SS are able to replicate their successes. Alcock (1981) quotes so many authors that the recurrent problem with psi is that the phenomena are not repeatable: "Philosopher Antony Flew did not always speak with the profound skepticism that he does today. In 1953 he published his first book. A new approach to psychical research, in which he argued that although there was not a repeatable experiment, and although there was a lot of nonsense perpetrated by charlatans, nonetheless one could not dismiss the case as closed.... Yet 25 years later, found himself disillusioned by the lack of progress. '....the research has indeed gone on. In all probability, its sum in the years between is as great or greater than the total for all the years before. Yet it is hard to point to any respect in which the general situation is better now than it was then. Certainly there is still no repeatable experiment to demonstrate the reality of putative psi phenomena' (Flew I979, p 3)".

12. It was necessary to discuss with magicians, possible non-paranormal means by which this performance could be made. 'Magical' techniques included (i) substitution of the test crumpled ball with a similar ball by sleight-of-hand, and the performer's reading of the test ball's contents. Direct observation by the investigators, the fact that the "psychic' on some occasions on which he was correct did not touch the test ball, and evidence from the video 
recording, exclude this device. (ii) reading of the writings on the test ball through impressions left on a surface on which the writings were made. The writings on the test ball made outside the 'psychic's room, eliminate this device. (iii) skilful suggestions made by the 'psychic' to the experimenter, to direct the writing of items. The writing of the items before the investigator confronted the 'psychic', and the writing of the items (unknown to the investigator), by a third person, exclude this.

13. Some personal details on himself were provided by B. He (birth year 1960), has been a vegetarian, teetotaller, and non-smoker, and has been meditating since he was 17 . He studied arts subjects and the occult in Nagpur, India for 6 years since the age of 14. Guidance in occult matters was from an Indian master. On his return to Sri Lanka he graduated (1984) in 'arts' subjects (including Economics and Logic) from a Sri Lankan University. He is married to a lawyer, and has 2 children (who do not show any psychic capabilities).

His capacity for accurate readings wanes after about 5 hours of continuous readings for clients. Likewise illness decreases his capacity. He does not give readings on full moon (Poya) days. He admitted that he has experienced a decline of his capabilities after he recently ceased to be a teetotaller.

14. An identical experience was documented by James Cameron (1974) with a guru in India who verbally reproduced with accuracy, 3 questions written by Cameron on a piece of paper, which he folded, placed inside an envelope, gave the assistant who placed it on the guru's desk. The latter touched it with his finger tips for a few seconds, consulted a Sanskrit chart with symbols, thought and then verbally reproduced exactly Cameron's questions. He discussed the contents with predictions.

15. In all the books on the paranormal, written by western authors which Inv has read, he did not come across any description of psi-phenomena of the sort described in this study. B and SS in Sri Lanka, Cameron's guru and the Indonesian might justify such a study.

16. This phenomenon was discussed with two amateur magicians. The first was able to read a concealed item written on a piece of paper that was crumpled. The technique appeared to be substitution of the original ball by a blank ball by sleight of hand during the intimate handling of the original by the magician, and his reading of the contents below the level of the table. This magician declined to reveal his technique. The second magician (an engineering academic don) explained how he also made correct readings on a rolled-up slip. The subject was asked to throw the roll with shells on a chart. The magician told him that he was incorrect in how he threw them, and proceeded to demonstrate elaborately; during the course of the demonstration he substituted the original roll with a blank piece of paper rolled-up, read it, and then quickly removed the counterfeit roll and the shells in case the subject opened the roll (to see the blank piece of paper).

\section{CONCLUSIONS}

1. B (19 sessions) and SS (4 sessions), both professional 'psychics', have repeatedly demonstrated their ability to read correctly, by apparently non-sensory means or conventional GESP, words, questions, figures and Zener, and computer-generated symbols written on slips of paper, which were crumpled and placed before them. Correct readings were possible even when the writings were made on slips of paper which were crumpled into small balls before the experimenters entered B's room for the sessions. The symbols were either known or unknow'n to the experimenter. The sequence of multiple sy'mbols too was correctly identified. Recognition of coloured writings, was also demonstrated. A device, 
gumming the paper before crumpling into a ball, used to prevent a fraudulent attempt at opening of the crumpled, unopenable ball did not prevent B, the only 'psychic' tested with this device, from achieving a score of $100 \%$. Fraud through reflecting surfaces, and direct vision of writing, was guarded against and excluded.

In 3 sessions B apparently demonstrated psychokinesis in having 'etched' his readings on leaves and on paper without handling them. This phenomenon was not further investigated.

B's scores were as follows-

SPECIFIC QUESTIONS OR SENTENCES

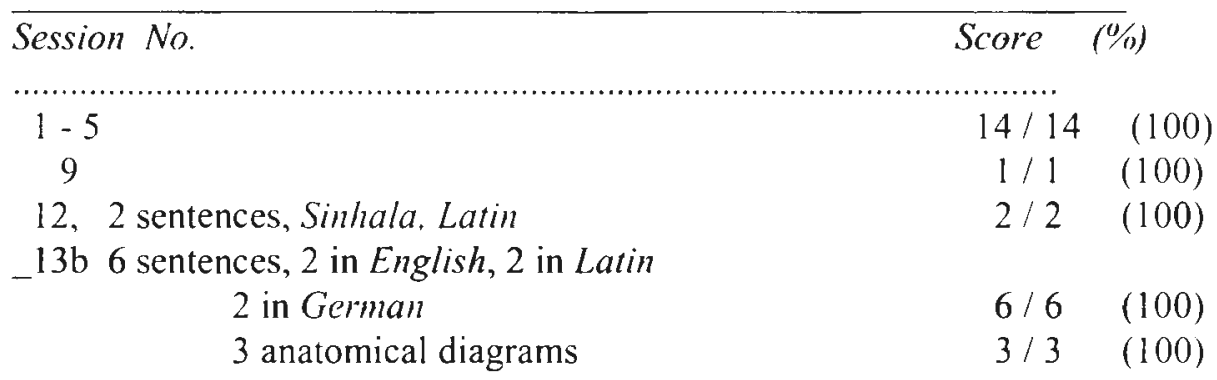

SYMBOLS

Session No.

Content

Score ("1)

\begin{tabular}{|c|c|}
\hline Zener symbols (unfamiliar to B) & $4 / 0 \quad(40)$ \\
\hline Zener symbols (familiar to B) & $10 / 10(100)$ \\
\hline " & $25 / 25(100)$ \\
\hline " & $13 / 13(100)$ \\
\hline " & $10 / 10(100)$ \\
\hline $\begin{array}{l}\text { computer-generated symbols, unknown to } \\
\text { experimenter }\end{array}$ & $(100)$ \\
\hline “ & $(\mathrm{I} 00)$ \\
\hline Zener symbols, Greek alphabet som & $(100)$ \\
\hline $\begin{array}{l}\text { computer-generated symbols, } \\
\text { unknown to experimenter }\end{array}$ & $4 / 5$ \\
\hline serial numbers of 2 currency notes & $2 / 2$ \\
\hline $\begin{array}{l}\text { Zener symbols with the gummed technique } \\
\text { to prevent fraudulent opening of the ball. }\end{array}$ & \\
\hline Symbols known to the experimenter & $5 / 5 \quad(100)$ \\
\hline 3 test items, 2 mystical symbols from & 1 identical \\
\hline $\begin{array}{l}\text { P.D.Ouspensky, on a gummed slip/ball } \\
\text {-a letter from the Sinhala alphabet from a } \\
\text { letter written earlier by B to me, also on } \\
\text { the gummed slip/ball }\end{array}$ & 1 similar \\
\hline 3 symbols, hand-written & $(100)$ \\
\hline 5 symbols, hand-written & $(100)$ \\
\hline
\end{tabular}


symbols, hand-written in sessions $6,11 \mathrm{~b}, 16,17$; computer-generated and printed in $11 \mathrm{a}, 1 \mathrm{lb}$ and $13 \mathrm{a}$

2. Beyond the reproduction of what was written (presence of clairvoyance?), one psychic was unable to discuss correctly (absence of telepathy?) the context, unspecified in the writing, of each question, nor was he able to make accurate predictions, based on the topics written (precognition). Another psychic (SS) was however able to comment accurately on the context of even one-worded questions which gave no clues to their context.

3. The means by which B and SS achieved their repeated successes, (with fraud through mirrors, sensors, eliminated as far as possible), are obscure. The only possible fraudulent method which could have been used was removing the ball by sleight-of hand, reading it, re-crumpling the ball before replacing it on the table but video-recordings excluded these. The sealing of the slips with adhesive internally before the slips were crumpled into balls, did not prevent B from reading the contents correctly. The sealed balls, when examined after the sessions, showed no evidence of having been opened during the session with B. Other aids to fraud, such as mirrors, were excluded.

The same technique was used by both B and SS. The similarity of the chart techniques of B and SS, which they claimed were 'learned' in India, suggests that this technique was essential for correct readings.

4. B was apparently able to psychokinetically etch on paper and on betel leaves, without the act of writing, his impressions of what he 'saw' written on the slips of paper which had been crumpled. A further investigation of this phenomenon was not done.

5. The performances of B ( 19 sessions) and SS ( 4 sessions) did not demonstrate either the 'decline effect' or the 'sheep-goat effect' which have been found with Zener card runs.

6. Items 4 and 6 suggest that the successful performances of B and SS were not identical with successful Zener card tests, and that a different mechanism (other than "clairvoyance' or 'telepathy'), or the mediation of 'discarnate intelligences' may have been used.

7. Techniques used by magicians to make similar performances, were excluded by the technique of the gummed ball (session 16) or slip (session 17).

8. The conditions used by both B and SS confirmed that "And several sources point to the occurrence of ESP during such meditational and contemplative procedures" (Green 1962-63). "The correspondence between the conditions that seem to be best suited to telepathy and those which occur in meditation is so close that it is tempting to pursue the parallels even further. All the groups that practise meditation also have very strict rules governing their diet. They are almost entirely vegetarian for ostensibly moral reasons, but there could also be a physiological basis for their food preferences" (Watson, 1974). "This means avoiding sensory activity and becoming as abstracted as possible, and probably. explains why many psychic subjects prefer to work in the dark or atleast in dim lighting, and all of them insist on quiet" (Watson, op.cit.).

9. The use of shells and chart by B recalls the procedure in reading the Chinese Book of Changes or I Ching: "To form each of the traditional patterns, the person consulting the 
oracle divides a number of yarrow stalks or tosses coins to get what amounts to a yes or no answer. This is done six times in succession, so that the final result is a hexagram, or pattern composed of six horizontal lines, which are either intact or broken, according to the results of the draw. There are sixty-four possible combinations of the two types of line and each of these hexagrams has a name and a traditional interpretation" (Watson, op.cit.).

"... if a comparison of the conditions is involved in the test, the unavoidable development of a preference on the part of a subject is likely to play a part in the delicate mechanism which decides whether the subject will hit or miss the target" (Rhine \& Pratt, 1957. p.98)

"If the subject appears to be working hard on each trial, it is wise to break up the run into sections" (Rhine \& Pratt, 1957; see also Inglis 1985) justifies the instalment procedure we used.

10. Our use of stringent conditions for prevention of fraud complies with the statement: "It is because the claims of parapsychologists would be of such extreme importance, if true, that extraordinary precautions are needed" (Alcock, op.cit.). "What is required is a solid. reliable demonstration of a phenomenon to study. Once that is found (if it can be found), parapsychologists will be in danger of being pushed aside in the stampede of researchers from all domains of science who want to study what would surely be the most exciting discovery in the modern history of science" (Alcock, op.cit.).

"Thus replicability is even more important in parapsychology than it is in normal science and this brief review should make it clear to the reader that the onus still rests with the parapsychologists to deliver what the sceptic has demanded for so long - an experiment that is replicable by anyone who makes a careful effort to replicate it." (Alcock, op.cit.). "A high degree of replicability, in this writer's opinion, is essential to both the progress and the recognition of parapsychology." (Adrian Parker 1978, quoted by Alcock, op.cit.). ".... if it has no clear rationality it's only chance of demanding scientific attention is replication" (Gardner Murphy 1971, quoted by Alcock op.cit.). "However, with regard to Beloff's sensitives, it should be noted that not a single person has ever been found who could demonstrate psychic powers to the satisfaction of independent investigators (Hansel 1980. quoted by Alcock, op.cit.). It would appear that B adequately met Hansel's and Alcock's challenges

The question, was Colnv-10 a psi-inhibitor, is prompted by Inglis's comment; "Can it be that experimenter-effect may work not just at the psychological, but also at the parapsychological level, so that individuals who are psi-inhibitors may be exercising their inhibitory influence on subjects through ESP?" (Inglis, op.cit.).

11. The performances of B with diverse test items answer Taylor's question (Taylor, op.cit.): "What can be sensed clairvoyantly - pictures, or words as well, and what range of discrimination occurs? Can musical notes be sensed? Colors?"

Pedler (1981) documented two experiments of Targ \& Puthoff, on remote viewing of the Louisiana Superdrome, and the ironwork of a foot-bridge. The 'seen' drawings were similar but not identical with the original targets, contrasting with the $100 \%$ congruence of 'seen' items by B and by SS in our experiments.

12. The mechanism of anomalous cognition by B and SS makes relevant the comments of Cornelissen (2010): ".... a concealed omnipresent omniscience might actually be the aspect of reality that is needed to understand 'anomalous cognition' " (p 133); "... there is consciousness and knowledge throughout the universe, in cach little particle, force or entity; 
and finally that there is a power in nature that pushes not only towards increasing complexity, but also towards the embodiment of increasingly sophisticated forms of consciousness" (p 145).

\section{ACKNOWLEDGEMENTS}

The author thanks are due to the two 'psychics' B and SS for their cooperation, the co-investigators for their participation; and to Professor Robert Morris (Arthur Koestler Chair, University of Edinburgh, recently deceased) for having suggested the final confirmatory test.

\section{REFERENCES}

Alcock, James E. 1981, Parapsychology: science or magic. Oxford, Pergamon Press. Cameron, James. 1974, An Indian Summer, London, Penguin Books, pp 60 - 64.

Cornelissen Matthijs. 2010, Anomalous cognition in the light of Sri Aurobindo's Theory of Knowledge. In: Yoga \& Parapsychology: Empirical research and theoretical studies. K. Ramakrishna Rao (ed.). Motilal Banarsidass, Delhi, India. pp 125 - 146. Ellis, Keith. 1974, Science \& the supernatural. London, Wayland Publishers Ltd. Green, Celia. 1962-1963. Finding objective criteria for E. S. P. Research Reviews. 228.

Inglis, Brian. 1985, The Paranormal. An Encyclopedia of Psychic Phenomena, London, Paladin Grafton Books.

Inglis, Brian. 1992, Natural and Supernatural. A history of the paranormal. Dorset, Prism Press.

Inglis, Brian. 1989, (with Ruth West and the Koestler Foundation). The Unknown Guest. Coronet Books.

Koestler, Arthur. 1972, The Roots of Coincidence. London, Hutchinson.

May, Edwin C. 1996, The American Institutes for Research Review of the Department of Defense's STAR GATE program: A commentary, Journal of Scientific Exploration, 10 (1): 89 - 108.

McConnelI, R.A. 1983, An introduction to parapsychology in the context of modern science. University of Pittsburgh.

Ostrander, Sheila \& Schroeder, Lynn. 1970, PSI. Psychic discoveries behind the Iron Curtain., London, Abacus.

Pedler, Kit. 1981, Mind over Matter. A scientist's view of the paranormal.London, Thames Methuen.

Rhine, J.B. \& Pratt, J.G. 1957, Parapsychology, Oxford, Blackwell Scientific Publications.

Taylor, John. 1980, Science and the supernatural; an investigation of paranormal phenomena. London, Granada.

Thouless, R. H. 1972. From anecdote to experiment in psychical research. London, Routledge \& Kegan Paul.

Watson, Lyall. 1974, Supernature. A natural history of the supernatural. London, Coronet Books. 